\title{
Reflections
}

\section{The fragility of welcome - commentary to Gill}

\author{
JONATHAN DARLING
}

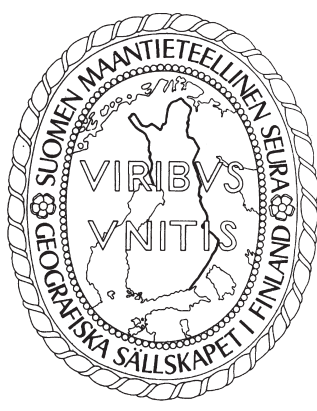

Darling, J. (2018) The fragility of welcome - commentary to Gill. Fennia 196(2) 220-224. https://doi.org/10.11143/fennia.75756

In this commentary, I take Nick Gill's discussion of the 'suppression of welcome' and the politics of hospitality, as a starting point for reflection on how 'cultures of welcome' are produced. In exploring the work of those supporting asylum seekers and refugees in Sheffield, UK, I argue that welcome may encompass a range of practices, with varying levels of intention and recognition attached. Yet what draws these practices together are two factors, first, a positive engagement with difference that holds the potential to promote solidaristic, or at the very least non-violent, relations. And second, a fragility that means that welcome is always at risk of being suppressed or commandeered for other purposes. In considering the implications of the 'suppression of welcome', I argue for a focus on welcoming as a negotiated process that involves varying durations, demands and levels of commitment.

Keywords: asylum, hospitality, ethics, sanctuary

Jonathan Darling, Department of Geography, Durham University, Science Laboratories, South Road, Durham,DH1 3LE,UK.E-mail: jonathan.m.darling@ durham.ac.uk

\section{Introduction}

Over a decade ago I began fieldwork in a drop-in centre for asylum seekers and refugees in the city of Sheffield, UK. Twice a week, asylum seekers, refugees, and volunteers would gather in a small hall to discuss their lives, share experiences, practice language skills, and develop friendships. For a year, I was part of this routine as I studied the practices of hospitality that shaped Sheffield's response to asylum (Darling 2011, 2014). In reading Gill's (2018) discussion of the 'suppression' of welcome in a context of both grassroots support for the 'refugee welcome' movement and a growth in right-wing nationalism across Europe, I was reminded of Sheffield and of two prominent signs I encountered during my time in the city.

The first hung at the entrance to the drop-in centre. The sign, a hand-painted montage of different colours on a white background, read 'Welcome' in thirty-six different languages. English, French, Mandarin, Russian, Urdu, Welsh, all competed for prominence on the board, and were all written by different hands. The sign was intended to represent all of the languages and dialects that the drop-in had encountered among its members, with new 'welcomes' being added if members arrived with new languages. It represented a form of cosmopolitan openness that was a source of considerable pride amongst the members of the drop-in.

The second sign occupied the windows and doors of a number of cafes, public buildings, and churches in the city. In white lettering on a red background, it read 'We welcome asylum-seekers and 
refugees', and was an indication of support for the City of Sanctuary movement. City of Sanctuary, at this point, was very much in its infancy, a movement organised by two residents of Sheffield to promote a 'culture of welcome and hospitality' in the city (Barnett \& Bhogal 2010). It would later grow into the nationwide movement it represents today, comprising a network of grassroots groups focused on advocating for the rights of asylum seekers and refugees. During the movement's infancy I witnessed the gradual multiplication of these 'welcomes' across Sheffield as an indication of growing public support for sanctuary in the city.

In this commentary, I want to reflect on the forms of welcome that these two signs represent, and to consider how such welcome is 'suppressed' in Gill's (2018) terms. I argue that welcome may encompass a range of practices, with varying levels of intention and recognition attached. Yet what draws these practices together are two factors, first, a positive engagement with difference that holds the potential to promote solidaristic, or at the very least non-violent, relations. And second, a fragility that means that welcome is always at risk of being suppressed or commandeered for other purposes. In what follows, I foreground both of these factors to argue for a focus on welcoming as a negotiated process that involves varying durations, demands and levels of commitment. Welcome, to be effective, must have some endurance. In this sense, I argue that to be welcoming is not a baseline condition that is suppressed by social and political forces, as Gill (2018) implies, but rather a practice that involves considerable work to achieve. To explore these tensions further, I begin by considering what 'welcome' might mean.

\section{Cultures of welcoming}

Etymologically, 'welcome' refers to an individual whose arrival is pleasing, or an arrival who is desired in some way. As such, to be welcome, or to be welcomed, should be a pleasant experience, one should feel the warmth of being desired and the reassurance that others feel pleased to be in your presence. Thus, as Gill (2018) argues, welcome is an interpersonal dynamic, an emotive and affective relation that conveys the pleasure we might feel in the company of others. Yet at the heart of Gill's (2018) discussion of welcome are the tensions that come to the fore when this welcome becomes something more than an interpersonal relation. In particular, Gill is concerned with how welcome comes to bear the weight of ethical and political reflection on migration, hospitality, and rights, and of how a culture or presumption of welcome has been abused by states in an effort to exclude migrants (Gibson 2016). One such tension lies in the distinctions between "the official response and the grassroots response" that Gill $(2018,90)$ notes in relation to the 'refugee crisis'. Another lies in the distinction between welcoming as a form of interpersonal relationship, and welcoming as a more generalised ethos or ethic. It is this latter distinction that is highlighted if we consider the two signs I encountered in Sheffield.

The first, at the entrance to the drop-in centre, was a singular expression of welcome. A hand-made sign produced specifically for this hallway and unique in its design, colours, and set of languages. In the years since, I have seen many similar 'welcome' signs, often displaying a similarly cosmopolitan mix of expressions. But each is in some way unique. The qualities of this sign reflected the practice of welcome undertaken by those attending the drop-in centre itself. This was a space in which welcome was performed in the ways that Gill foregrounds, as those present in the drop-in centre were offered "a perception that [their] presence brings about joy or satisfaction in someone else" (Gill 2018, 90). The drop-in centre was a space for meeting and making friends, supporting one another, sharing food, drink, and stories, and enjoying the presence of other people. It was therefore a space founded on the importance of welcoming, of conveying a pleasure in meeting others and sharing time with them. Tasks of guidance and support were certainly undertaken here, from translating Home Office letters and offering advice, to providing food supplies to those with no recourse to public funds, yet in the main the drop-in centre was a space for people to offer their time, and their presence, for being with others. I would thus argue that it represented one of the many spaces of welcome that Sparke $(2018,215)$ refers to as "in-between spaces" in which the violence of an exclusionary asylum system is "contested and countered, however incompletely". However, it is important to note that this was a very specific space, and a specific form of welcome. Welcome was arrived at here through considerable 
hard work on the one hand, from both the volunteers and the asylum seekers who together created an environment in which all could feel safe, and considerable trial and error on the other, with questions over who had access to resources and what expected roles volunteers should play coming to the fore. The culture of welcome that operated here was not pre-given, it was developed and refined as members negotiated how they wanted to interact with each other, what they wanted from the space, and how those expectations were recast as new members brought their own ideas and experiences to bear on it. At the same time, this was an intentional welcome, shared and embodied through the choice to be present. It is this that distinguishes it from the second mode of welcoming.

The second mode is tied to the presence of City of Sanctuary 'welcome' signs across the city. These signs were precisely not the singular and interpersonal expression of the drop-in centre. They were professionally designed and printed, and distributed to businesses that supported the social movement. They expressed a much broader sensibility of welcome, one not tied to specific acts or forms of friendship, but to a generalised disposition towards asylum seekers and refugees. The businesses that displayed such signs were not committing themselves to employing, accommodating, or training asylum seekers necessarily, although some did offer voluntary opportunities for asylum seekers as a means to address social isolation and cultural barriers in the city (Darling \& Squire 2013). Rather, they were committed to displaying an affinity with a message of support for asylum seekers and refugees in the midst of an otherwise repressive political and public mood towards migration of all forms. These signs did not indicate the kind of highly personal welcome that developed in the drop-in centre. Instead, they sought to indicate a less demanding and less personal sense of welcome, of a generalised support in public for asylum seekers and refugees in the city. In this way, they were one part of a series of minor gestures of sociality that could make people feel welcome, even if only momentarily.

It was this accumulated sense of welcoming that asylum seekers referred to in interviews when discussing what made the city feel 'welcoming'. Smiles and nods from passers-by in the street, a kind person offering directions to an otherwise lost new arrival, bus drivers interrupting their routes to point out the shortest way home, conversations started with strangers about the weather in doctors' waiting rooms, all of these were cited as examples of how 'welcoming' the city and its people were. In this context, the public display of signs reading "We welcome asylum seekers and refugees" became a means of reiterating the sociality of welcoming, and was seen by asylum seekers in Sheffield as a positive indicator of the friendliness of the city. Indeed, the relatively modest nature of such signs, and the lack of expectation attached to them, meant that they reached a far wider constituency than the more demanding relations of the drop-in centre.

These two signs thus point us to two modes of welcoming. On the one hand, the City of Sanctuary signs and the ethos of welcome they expressed in public space, reflect a sociality that involves minor gestures of welcome and civility. These are moments of kindness, even possibly warmth towards strangers, but they are not enduring relationships. On the other hand, the drop-in centre and its more personal practice of welcoming, expresses a commitment to welcoming strangers that seeks to forge lasting connections between individuals, to promote forms of solidarity between those present, and to position the feeling of being welcome as a shared experience. For those asylum seekers I worked with in Sheffield, these two modalities of welcome worked together to shape a sense of the city as welcoming, and to offer that form of respite that Sparke (2018) notes in his discussion. Respite of this kind is part of the emotional contours of refuge, as it can offer minor points of coping that can, as Vainikka and Vainikka $(2018,125)$ note in their commentary, be incredibly important in promoting a "sense of certainty and security" amidst the insecurity of the asylum system. It is this insecurity that Gill (2018) returns to in highlighting the 'suppression' of welcome, and I want to now consider how such 'suppression' may be intertwined with the labour of welcoming.

\section{Indifference to welcome}

The suppression of welcome is, as Gill (2018) illustrates, a multifaceted process. It encompasses the rise of far-right nationalists, the increasing use of extraterritorial detention and processing to keep asylum seekers at a distance from diverse publics, and the pervasive labelling of asylum seekers as 
figures who 'abuse' the hospitality of the nation-state. These trends all place the culture of welcoming expressed in cities like Sheffield under threat. However, they may also serve to foster dissent and promote the critical articulation of alternatives, as Sparke's (2018) discussion of welcoming in the context of migrant activism illustrates. In the context of the UK though, two further trends place the articulation and maintenance of a public culture of welcome at risk. These are trends tied to a diminishing sense of asylum, and the demands of responsibility and justice that seeking asylum brings to the fore, as properly public issues or concerns.

The first trend is thus in the professionalization of welcome, such that welcoming loses its sense of interpersonal dynamic and becomes a transactional property. We might see parallels here to Friese's (2010) discussion of how migrants have been received on the island of Lampedusa, and how localised cultures of informal hospitality have been undermined by the emergence of professional support services. In this case, gestures of hospitality enacted by local residents, were transformed into forms of "good practice", and migrants were confined to segregated spaces and removed from public view as they became part of an emergent economy of "welcome" and "migration management" (Friese 2010, 334). The significance of this transformation is in how the enrolling of private actors and professional services can act to not only enclose mobility, such that welcoming becomes a procedural matter, but also that this insulation leaves no opportunity for other forms of relation to develop. What is lost in this context, is an exposure to others in ways not directly managed by a system of enforced mobility, or by a contractual relationship that conditions the forms that contact can take (see Wilson 2017). This mode of professionalization risks strictly defining the possibilities and limits of any form of welcoming, and undermining the grounds on which something like a 'culture of welcoming' might be developed.

In concert runs a second threat, one focused on the public sociality of welcoming discussed in Sheffield. In part this arises from decades of asylum and migration policy that has sought to coarsen public discourse on such issues. The privatisation of asylum accommodation and support services in the UK is one facet of this trend, but so too is the focus on creating a 'hostile environment' for migrants, such that policy is directed at deterring those not seen to be 'worthy' of welcome in the country. The effects are manifold, from a growth in xenophobia in public discourse to the structural marginalisation of migrant groups. But I want to foreground a more pervasive effect: that this coarsening of public mood has promoted a rise of indifference towards strangers. This is an indifference that does not set out to harm, but does not seek to welcome either. Of course, indifference may still be preferable to the anger and hatred generated towards migrants in recent years, and Sparke (2018) is right to remind us of the need to explore not just the emotional politics of welcome, but also the production of hate so readily associated with anti-immigrant positions. Yet there is an important need to also recognise that for many the politics of migration and refuge may also inspire apathy, resignation, or what Sontag (2003) termed "compassion fatigue". In this sense, public indifference also has its emotional and affective dimensions, not of rage or frustration, empathy and compassion, but of mild irritation, resignation, or of a briefly felt concern that never accumulates into a desire to act, or a need to be welcoming. There is then a need to consider not just how the rejection or suppression of welcome is fostered, but also how an indifference to welcome, and an indifference to strangers, is also shaping collective responses to claims for refuge.

\section{The durations of welcome}

In this commentary, I have focused on how the practice of welcome, and the production of a culture of welcoming, can be fragile and laborious. It involves not just progressive sentiments and interpersonal connections, but also hard work, commitment, and a desire to welcome others. It is the gains of this hard work, and the resonance of this desire, that is under threat as Gill (2018) draws our attention to. In response, he outlines various ways in which welcome might be protected and reanimated. I will not repeat these here, but I do wish to conclude by commenting on how such reanimation might proceed through a concern with acknowledging the multiple forms and durations that welcome may take.

If welcoming involves labour alongside its attributes of interpersonal warmth and consideration, then the duration of welcome matters. Beyond a singular moment of welcome, the process of 
welcoming entails the work of ensuring that strangers feel the sense of security and possibility that welcome implies, perhaps indefinitely. Welcoming as a process thus calls us to consider, as Vainikka and Vainikka $(2018,124)$ assert, the importance of who is undertaking this work of welcoming and how they are, or are not, able to maintain this process. As noted in Sheffield, different modalities of welcome demand different resources and capacities. The willingness to offer directions to an uncertain stranger demands far less than the commitment to teach conversational English once a week, or the willingness to begin new friendships with those experiencing the isolation of the asylum system. In both senses, being welcoming can be open-ended, it does not have a set duration or time limit, and this means that acknowledging the challenges of welcoming as a process, as a labour of different demands and expectations, is critical in responding to the suppression of welcome. Recognising the varying forms welcome may take is essential in finding ways to support and maintain the fragile cultures of welcome that do exist, not least because such cultures necessarily entail multiple modes of welcoming.

At the same time, as many responses to the so-called 'refugee crisis' illustrate, there is often an immediacy to the demand to welcome. It is in response to such immediacy that a 'culture of welcoming' either comes to the fore or is found wanting. It is this question of response, which returns us to welcoming as an ethical responsibility, for as Derrida (2002) argues, welcoming cannot be fully organised and known in advance, rather it represents a disposition towards others that is drawn upon in a moment, an ethics that is embodied and felt. It is this thread of responsiveness, of expressing welcome as a form of social justice, that runs through the varied modes of welcoming I have sought to foreground in this commentary. Such forms are not always successful in this endeavour, but it is in the labour of keeping such signs visible and keeping such friendships alive, that the ground work of maintaining a culture of welcoming is done. The fragile labour of welcoming is then a critical part of rediscovering;

a taste for living in a culture, a language, and a country in which hospitality is no longer a criminal offence, a country whose national representation no longer proposes to punish the welcoming of a foreigner, and in which no one again dares speak of a "crime of hospitality" (Derrida 2002, 144).

\section{References}

Barnett, C. \& Bhogal, I. (2010) Becoming a City of Sanctuary. Plug and Tap, Sheffield.

Darling, J. (2011) Giving space: care, generosity and belonging in a UK asylum drop-in centre. Geoforum 42(4) 408-417. https://doi.org/10.1016/j.geoforum.2011.02.004

Darling, J. (2014) Emotions, encounters and expectations: the uncertain ethics of 'the field'. Journal of Human Rights Practice 6(2) 201-212. https://doi.org/10.1093/jhuman/huu011

Darling, J. \& Squire, V. (2013) Everyday enactments of sanctuary: the UK City of Sanctuary movement. In Lippert, R. \& Rehaag, S. (eds.) Sanctuary Practices in International Perspectives: Migration, Citizenship and Social Movements, 191-204. Routledge, London.

Derrida, J. (2002) Negotiations: Interventions and Interviews, 1971-2001. Translated by E. Rottenberg. Stanford University Press, Stanford.

Friese, H. (2010) The limits of hospitality: political philosophy, undocumented migration and the local arena. European Journal o Social Theory 13(3) 323-341. https://doi.org/10.1177/1368431010371755

Gibson, S. (2016) 'Abusing our hospitality': inhospitableness and the politics of deterrence. In Molz, J. G. \& Gibson, S. (eds.) Mobilizing Hospitality: The Ethics of Social Relations in a Mobile World, 159175. Routledge, London.

Gill, N. (2018) The suppression of welcome. Fennia 196(1) 88-98. https://doi.org/10.11143/ fennia.70040

Sontag, S. (2003) Regarding the Pain of Others. Penguin, London.

Sparke, M. (2018) Welcome, its suppression, and the in-between spaces of refugee sub-citizenship - commentary to Gill. Fennia 196(2) 215-219. https://doi.org/10.11143/fennia.70999

Vainikka, V. \& Vainikka, J. (2018) Welcoming the masses, entitling the stranger - commentary to Gill. Fennia 196(1) 124-130. https://doi.org/10.11143/fennia.70227

Wilson, H. F. (2017) On the paradox of 'organised' encounter. Journal of Intercultural Studies 38(6) 606-620. https://doi.org/10.1080/07256868.2017.1386631 